tracing the relevant Minutes, and Mr. S. Wood of the Library staff for information on Cornelius Johnson. To Mr. C. K. Adams, Assistant to the Director of the National Portrait Gallery, we are greatly obliged for the trouble he has taken, and for his ready guidance. We are also indebted to Mr. F. N. L. Poynter and Mr. C. A. Earnshaw of the Wellcome Historical Medical Museum for their interest and help. To Dr. O. M. Duthie and Dr. E. Bosdin Leech of Manchester we are obliged for their help in the fruitless search for the history of the portrait prior to its presentation to the Royal College of Surgeons.

\title{
REFERENCES
}

Edmonson, J.-A Complete Body of Heraldry, London, 1780.

FInBerg, A. J.-The Chronological List of Portraits by Cornelius Johnson, or Jonson. London: Walpole Society, Vol. X, p. 1, 1922.

GuIllim, John.-A Display of Heraldry. 3rd edition. London; 1638.

Hallet, F. G.-Catalogue of Portraits and Busts in the Royal College of Surgeons of England. London, 1930.

JAMES, R. R.-Studies in the History of Ophthalmology in England prior to the year 1800. London, 1933.

and SorsBY, A.-Brit. Jl. Ophthal., Vol. XVIII, p. 156 (1934).

Power, D'ARCY-Proc. Roy. Soc. Med., Vol. VI, Sect. Hist. of Medicine, p. 18 (1913).

SorsBy, A.-(a) Brit. Jl. Ophthal., Vol. XVI, p. 166 (1932).

(b) ibid.

A Short History of Ophthalmology, London, 1933.

\section{SOME NEW POINTS IN THE TECHNIQUE OF IMPLANT IN TENON'S CAPSULE AFTER ENUCLEATION}

BY

\section{ALbert FaVORY}

\section{PARIS}

IN some cases the implant of "acrylic" or any other material within the sclera after evisceration is not advisable, especially when sympathetic ophthalmia is threatening; enucleation is then absolutely necessary, and an implant in Tenon's capsule with fixation of the four recti can be done to obtain a moving prosthesis.

An implant within the sclera gives better movements to the prosthesis owing to the fact that the six ocular muscles are keeping their mobility even admitting that they are weakened more or less after the operation.

Among the numerous techniques described, Cutler's operation presented at the recent Oxford Congress appears as very seductive and exhibits very good functional results. Nevertheless, our personal 
technique differs from Cutler's operation in many ways. The size and shape of the implant as well as the material used are not quite similar, so we shall emphasize these points of importance.

The fact that we should foresee a certain amount of shrinkage of Tenon's capsule after the operation led us to the opinion that the implant ought not to be too large; a ball of $10 \mathrm{~mm}$. diameter is

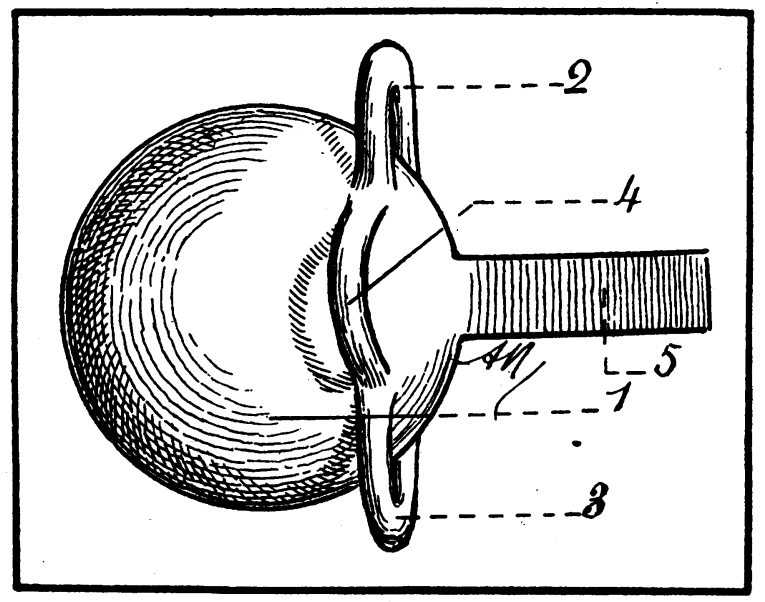

FIG. 1.

(After Virenque). Side view of implant. 1, body. 2,3,4, arches. 5 , spur.

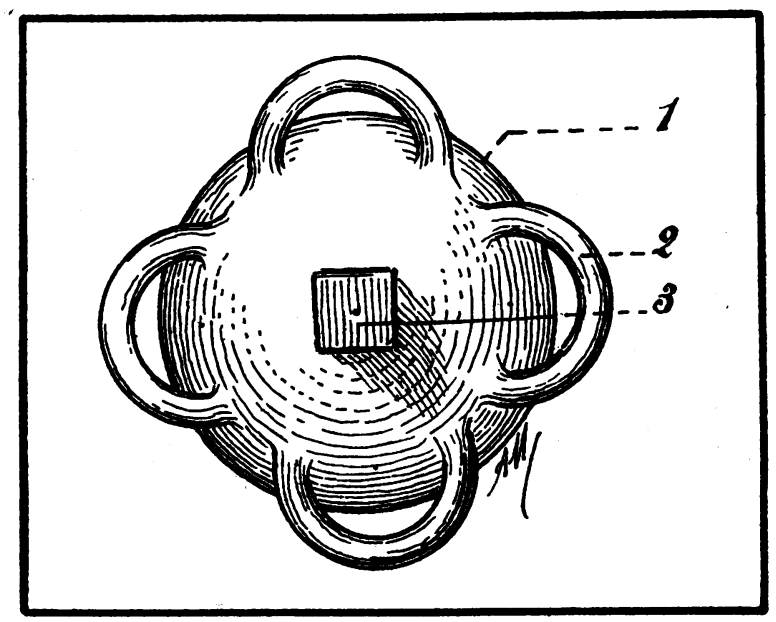

FIG. 2.

(After Virenque). Face view of implant. 1, body. 2, arch. 3, spur. 


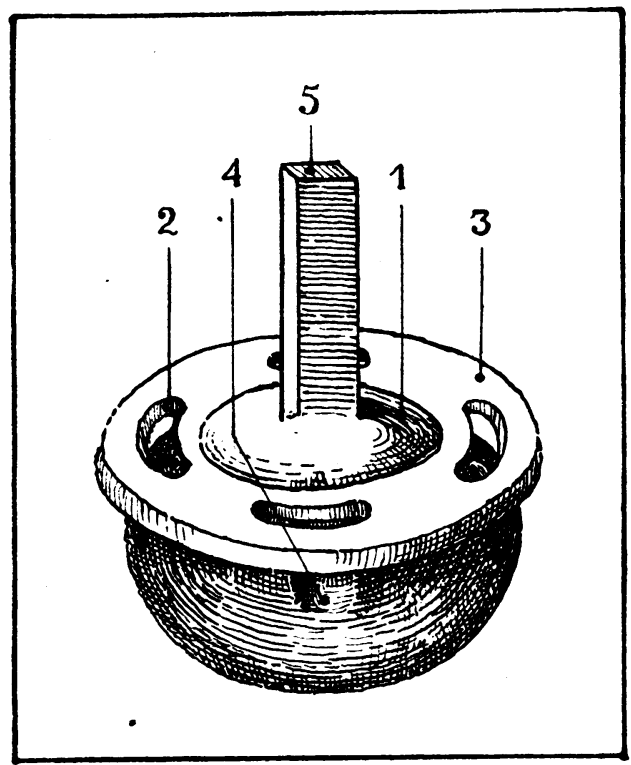

FIG. 3.

Face view of implant (new shape). 1, body. 2, oval-shaped hole. 3 , disc. 4, groove. 5 , spur.

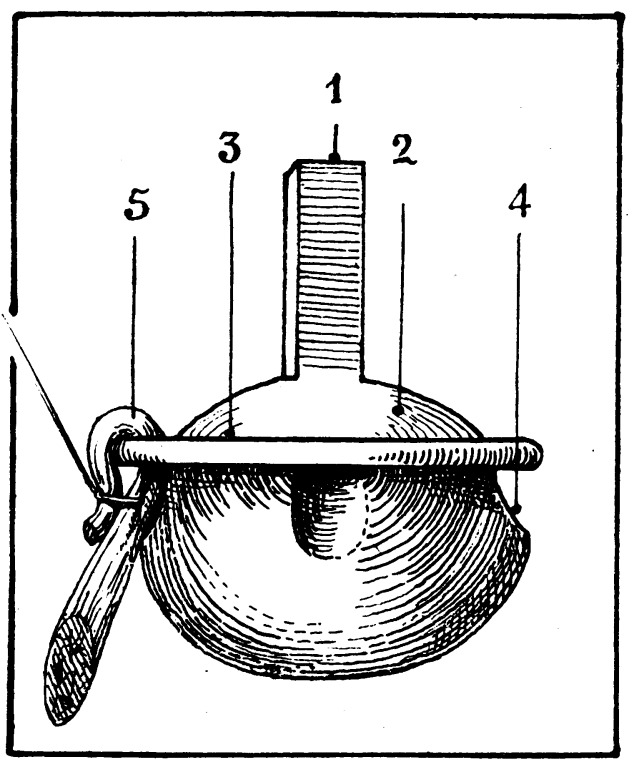

FIG. 4.

Side view of implant (new shape). 1, spur. 2, body, 3, disc. 4. groove. 5. muscle loop. 
sufficient, an excessive diameter may be the cause of its subsequent extrusion.

The only material used in our technique is " acrylic"'; we think that the addition of a golden ring and pin makes the piece too heavy, and probably gold is not as well tolerated as acrylic, notwithstanding the fact that gold is a very rare material here in France.

Our implant is spherical in shape, its posterior surface being slightly flattened; four little arches of the same material as the ball are fixed near the anterior surface to receive the tendons of the recti. On the anterior aspect a spur of $15 \mathrm{~mm}$. long and quadrangularly prismatic in shape is protruding (see Figs. 1 and 2 . In a new shape the muscles are fixed on a disc with oval-shaped holes. On the implant body are four grooves to ease the muscle looping (Figs. 3 and 4). The operation is done with local anaesthesia, using a 2 per

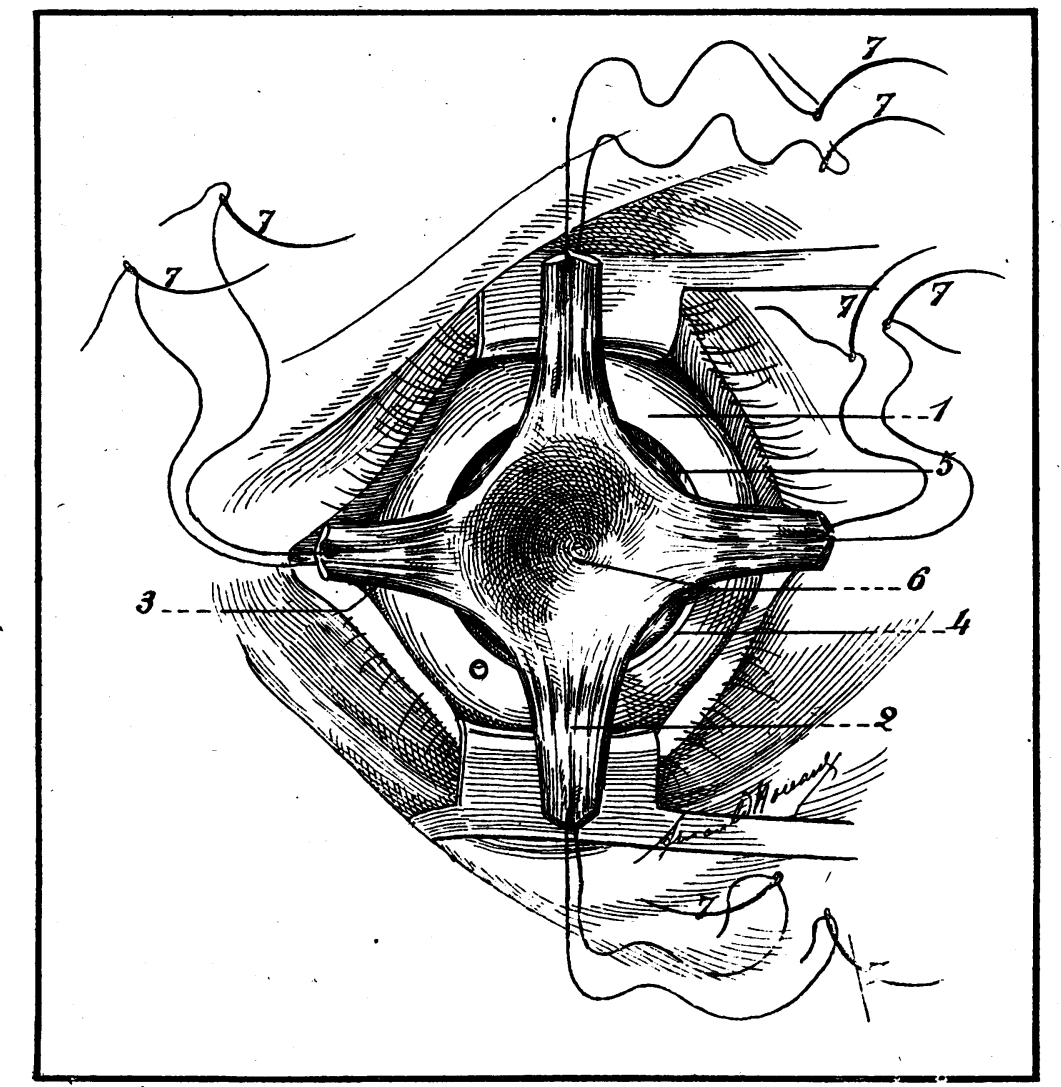

FIG. 5.

Enucleation complete (after Virenque). 1,4 and 5, orbital tissue. 2 and 3 , rectus muscle. 6 , Tenon's capsule. 7 , double armed silk stitch. 


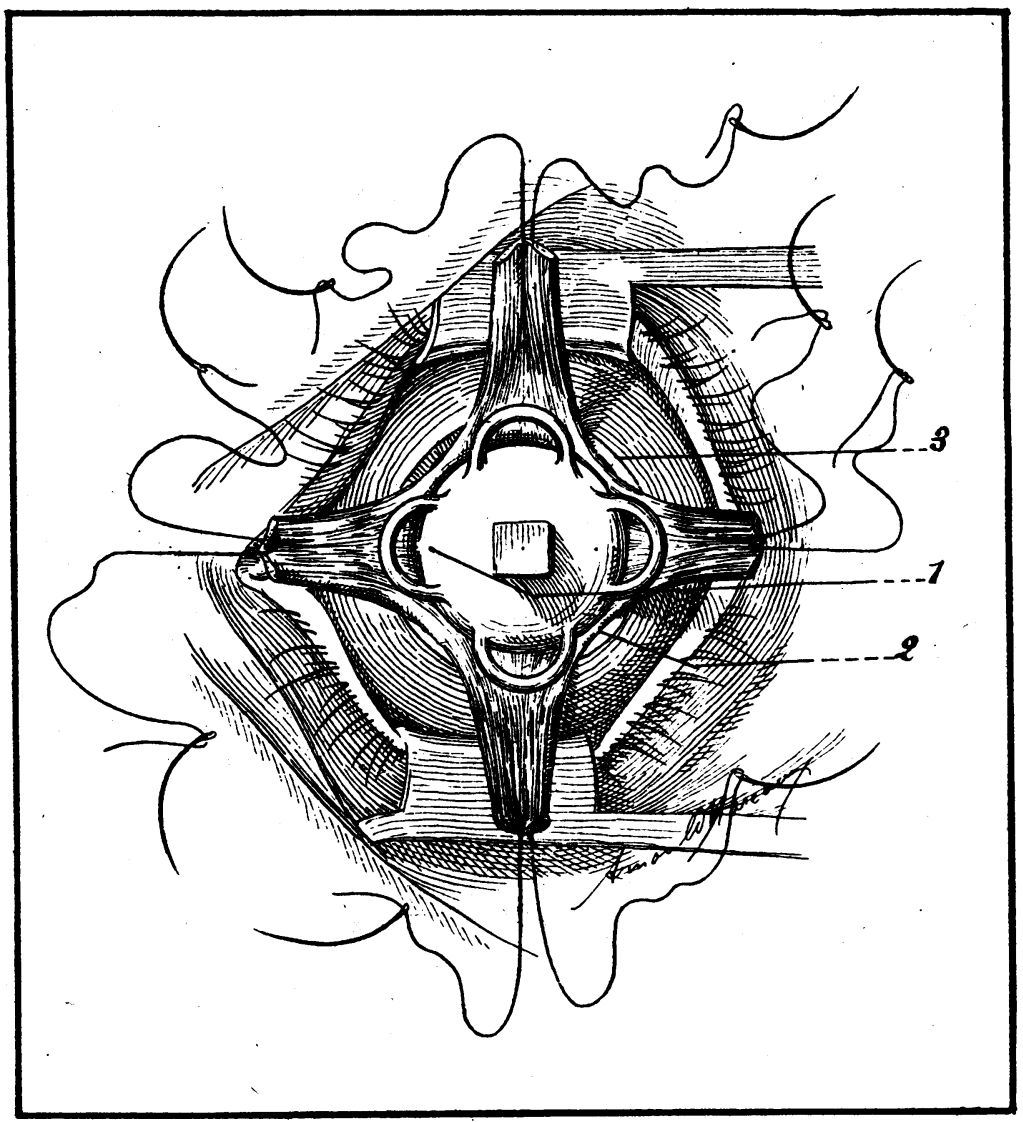

Fig. 6.

Implant placed in Tenon's space (after Virenque). 1, implant. 2, Tenon's capsule. 3, orbital tissue.

cent. solution of novocaine adrenalin for a retro-bulbar injection. It is not necessary to add to this solution 1 c.c. of 40 per cent. alcohol as is done in evisceration. The local anaesthesia is completed by injecting a few drops of the same solution within each rectus and subconjunctivally around the limbus. To keep the patient absolutely quiet, a subcutaneous injection is done one hour before the operation with nargenol (a mixture of morphia, scopolamine and ephedrine). We never use general anaesthesia.

The enucleation is performed in the usual manner, but a double armed silk suture is passed through the tendon of each rectus after this has been hooked. Then the eye is delivered, Tenon's capsule is inspected and haemostasis is carefully done with R.C. haemostatic (the main basis of this solution is extracted from pigeon muscle) (Fig. 5). 
The implant is held in place in Tenon's capsule by grasping the spur with the forceps (Fig. 6).

The suture holding each rectus tendon is passed through each corresponding arch or hole, the tendon is then looped through round the arch or disc, the two needles of each suture being passed through the tendon and the silk passed through the conjunctiva and tied over (Fig. 7).

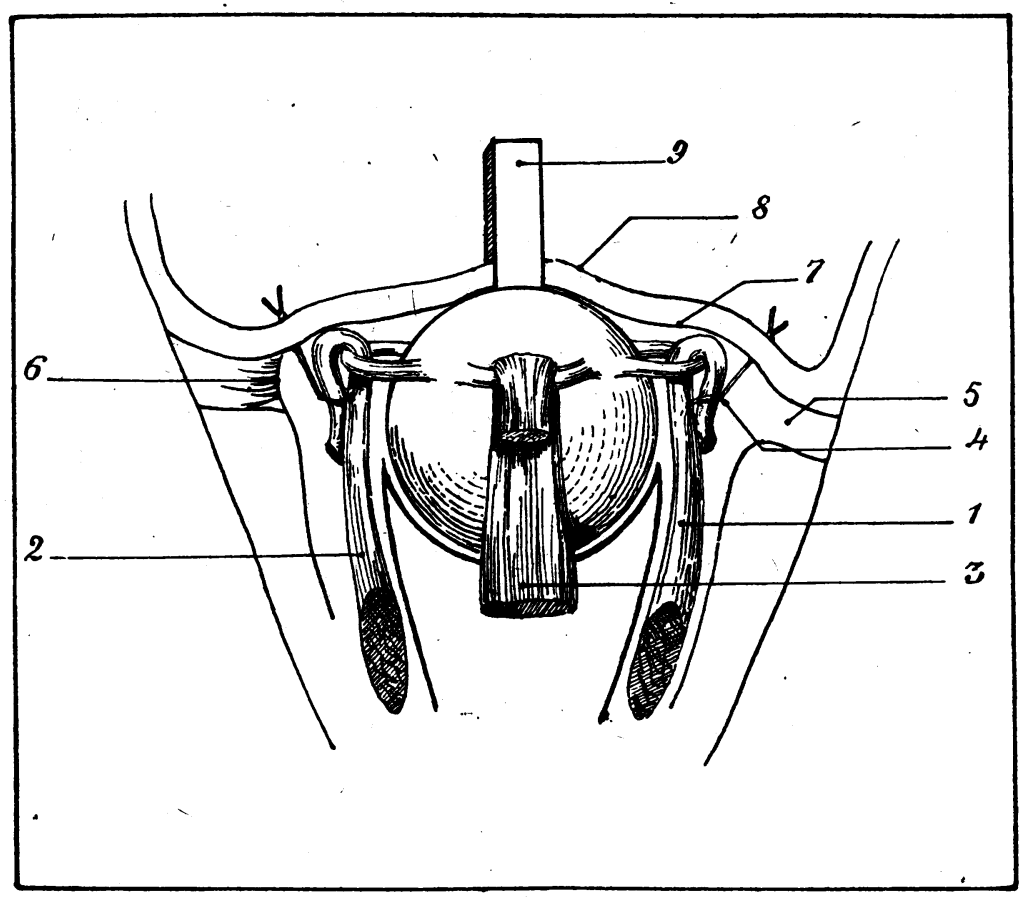

FIG. 7.

Semi-schematic cut of socket. $1,2,3$, rectus muscle. 4 , muscle stitch tied over conjunctiva. 5, Tenon's space. 6 , socket space. 7 and 8 ; conjunctiva. 9 , spur.

Tenon's capsule is sutured by separate catgut stitches and must be very carefully closed, conjunctiva is sutured over by five silk stitches each side of the spur (Fig. 8).

It seems that suturing the conjunctiva over the implant does not alter the deepness of the fornices owing to the conjunctiva's great elasticity.

At the end of the operation only the spur is protruding out of the conjunctiva and will later on enter a hole on the posterior surface of the prosthesis, A retainer shell is placed inside the lids to hold the implant and maintain the depths of the fornices. 


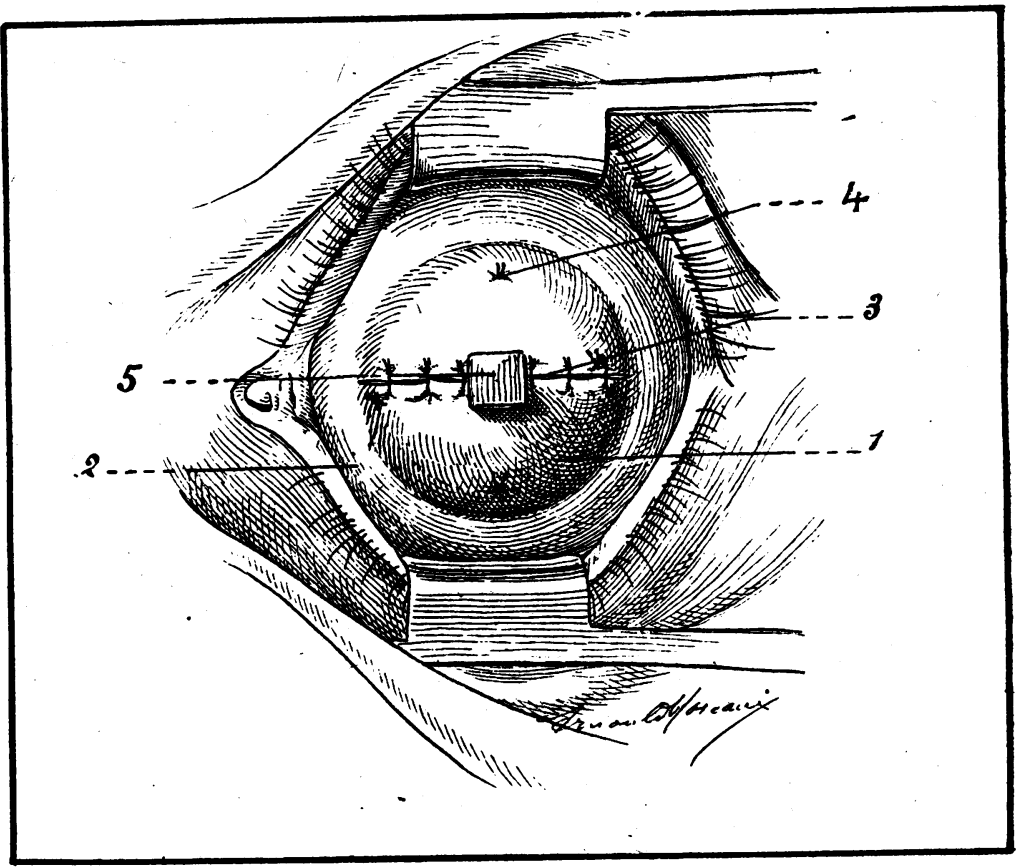

Fig. 8.

-Completed operation (after Virenque). 1, implant covered by conjunctiva. 2 , conjunctiva. 3 , conjunctival suture. 4, rectus suture. 5, spur.

Very little reaction follows the operation and the dressing is not changed until after six days. The stitches are removed after ten days and a mould of the anterior aspect is done. The posterior surface of the prosthesis is made from the mould and will then fit perfectly well.

The shell is removed and the prosthesis is inserted as soon as possible, even if it is a provisional one to maintain the shape of the fornices. The final prosthesis may be adapted some weeks later. It is too soon to judge of the final value of this technique, as we have performed only a few operations.

We observed elimination of the implant in our first case. This was a bad case with an abnormal socket, and the piece used was too large. In another case the implant became prolapsed owing to the lack of firm suturing of the muscles. We had used catgut instead of silk to fix the muscles. In the other cases we were satisfied with the functional and cosmetic results.

We look forward to proceeding in this way and improving our technique by making any necessary modifications to ease its performance and to better its results. 